\title{
E2F1/2/4 mRNA is associated with immune infiltration and are potential biomarkers for the prognosis of human gastric carcinoma
}

\author{
Yongyi Chen ${ }^{1,2}$, Wangang Gong ${ }^{2,3}$, Wumin Dai ${ }^{2,3}$, Huifen Jiang ${ }^{1,2}$, Xiaohong Xu ${ }^{1,2}$ \\ ${ }^{1}$ Department of Clinical Lab, The Cancer Hospital of the University of Chinese Academy of Sciences (Zhejiang Cancer Hospital), Hangzhou, China; \\ ${ }^{2}$ Institute of Basic Medicine and Cancer (IBMC), Chinese Academy of Sciences, Hangzhou, China; ${ }^{3}$ Zhejiang Cancer Research Institute, The Cancer \\ Hospital of the University of Chinese Academy of Sciences (Zhejiang Cancer Hospital), Hangzhou, China \\ Contributions: (I) Conception and design: Y Chen, H Jiang, X Xu; (II) Administrative support: W Gong; (III) Provision of study materials or patients: \\ W Dai; (IV) Collection and assembly of data: W Gong, X Xu; (V) Data analysis and interpretation: Y Chen, W Gong, X Xu; (VI) Manuscript \\ writing: All authors; (VII) Final approval of manuscript: All authors. \\ Correspondence to: Xiaohong Xu. Department of Clinical Lab, Zhejiang Cancer Hospital, No 1, East Banshan Road, Gongshu District, Hangzhou \\ 310022, China. Email: zjhzxxh@163.com.
}

\begin{abstract}
Background: E2Fs are genes that regulate DNA synthesis and the cell cycle by encoding a family of transcription factors. Increasing experimental evidence has revealed that E2Fs play key roles in tumor progression in various types of cancer.

Methods: We investigated the survival, expression and transcriptional data of E2F1/2/4 in gastric cancer (GC) patients using the immunohistochemistry assay, Kaplan-Meier Plotter, cBioPortal, String, and GEPIA databases. The plasma of GC patients was analyzed using the real-time reverse transcription polymerase chain reaction (RT-PCR) assay. The correlation between E2F1/2/4 expression and clinical features was analyzed using the quartile method. As well, the correlation between E2F1/2/4 and GC immune infiltration was also investigated using the TIMER database. Database of Immune Cell Expression (DICE) was also used to analyze correlations between SOX4 and immune responses.

Results: RT-PCR and tissue immunohistochemistry confirmed that E2F1/2/4 was highly expressed in serum and GC tissue samples of GC patients, the expression of which was not affected by patient age and gender. Also, the survival analysis revealed that low levels of E2F1/2/4 expression were significantly associated with a longer overall survival (OS) in GC patients. E2F1/2/4 was correlated with patient prognosis and immune cell infiltration, including $\mathrm{B}$ cells, $\mathrm{CD}^{+} \mathrm{T}$ cells, $\mathrm{CD}^{+} \mathrm{T}$ cells, macrophages, neutrophils, and DCs in GC. Our findings indicated that $\mathrm{E} 2 \mathrm{~F} 1 / 2 / 4$ could be used as a prognostic biomarker and indicator of immune infiltration in GC.
\end{abstract}

Conclusions: This study revealed that E2F1/2/4 could be a promising indicator for tumor-associated immune infiltration and prognosis in GC patients.

Keywords: E2F1/2/4; gastric cancer (GC); immune infiltration; bioinformatics analysis

Submitted Jan 08, 2021. Accepted for publication Apr 27, 2021.

doi: $10.21037 /$ tcr-21-45

View this article at: https://dx.doi.org/10.21037/tcr-21-45

\section{Introduction}

Gastric cancer (GC) is the third leading cause of cancerrelated death worldwide and the fifth most commonly diagnosed cancer (1). GC pathogenesis is a multistep and multifactorial process involving tumor gene mutations and epigenetic changes (2). Currently, although conventional tumor biomarkers such as carcinoembryonic antigen (CEA) and carbohydrate antigen 19-9 (CA19-9) have been widely 
used in the diagnosis of GC, they cannot be applied in the screening of early GC due to their shortage in terms of specificity and sensitivity (3). With the increasing studies on carcinogenesis in recent years, it has become increasingly important to search for indicators affecting the development and prognosis of GC at the molecular level and to develop targeted therapies. Currently, there are more and more drugs and studies targeting human epidermal growth factor receptor-2 (HER-2), vascular endothelial growth factor (VEGF), epidermal growth factor receptor (EGFR), serine/ threonine-protein kinase mTOR, immune checkpoints and other related pathways and targets, as well as certain breakthroughs have been achieved, but most of phase III studies of targeted therapies for GC, such as the EXPAND trial of cetuximab and GRANITE-1 trial of everolimus, showed a negative result (4-6). Currently, only angiogenesis and HER2 are the most promising and attractive targets in the treatment of GC, and the 5-year overall survival (OS) rate still remains poor $(4,7)$. Therefore, further exploration and research are needed in the fields of etiology and molecular diagnostics of GC, and new biomarkers with high specificity that can be detected early and lead to treatment options are developed. Thus, there is a need for potential prognostic biomarkers and drug targets for GC.

In mammalian cells, E2Fs are a series of genes encoding transcription factors (8). E2Fs can be divided into 2 groups according to their functions. E2F1, E2F2, and E2F3a function as transcriptional activators (9); whereas E2F4-8 and E2F3b act as transcriptional repressors (10). Moreover, E2Fs regulate a series of biological effects, including DNA synthesis, gene expression and cell cycle regulation (11). Moreover, E2Fs are closely related to various cancers' progression and are widely expressed in different types of cancer tissues (12).

Previous studies have identified a total of $\mathrm{E} 2 \mathrm{~F} 1 / 2 / 3 / 4 / 5 / 6 / 7 / 8$ factors in mammalian cells (13). A recent study identified that E2F1, E2F2, E2F3, and E2F8 function as oncogenes in lung cancer (14). E2F1 plays a conflicting role in different types of cancers as it exhibits tumor-suppressing activity in gastric, esophageal, and colorectal cancer, but displays the opposite function in pancreatic ductal adenocarcinoma and esophageal squamous cell carcinoma (15). E2F1 also affects the epithelial to mesenchymal transition to promote the progression of GC. A recent study also indicated that E2F6 promotes gastric carcinoma progression by downregulating lncRNA CASC2 (16). However, little is known about the features and prognosis induced by an abnormal expression of
E2F1/2/4 expression in GC (17). Clinical performance of E2Fs 1-3 in kidney clear cell renal cancer, evidence using a bioinformatics analysis (18). Also, a previous study analyzed the expression and mutations of E2Fs in GC (19). Based on these analyses, E2Fs were found to be correlated with infiltrating immune cells level, such as $\mathrm{CD}^{+} \mathrm{T}$ cells, $\mathrm{CD} 8^{+}$ $\mathrm{T}$ cells, and DCs in GC patients. Our results suggested that E2F1/2/4 functioned as biomarkers for determining the prognosis and immune infiltration in GC.

We present the following article in accordance with the MDAR reporting checklist (available at https://dx.doi. org/10.21037/tcr-21-45).

\section{Methods}

\section{GEPIA analysis}

The transcription levels of E2Fs in GCs was analyzed in an online cancer microarray database GEPIA database (www. oncomine.org).

\section{Survival analysis}

Kaplan-Meier Plotter online database was used to evaluate the prognostic value of E2FS in GC patients as previously reported. Data of gene expression and patient survival were obtained from TCGA database (http://www.tcga. org/) and the Kaplan-Meier plotter (http://kmplot.com/), respectively. The details of data analysis were as previously described $(20,21)$.

\section{Database of immune cell expression (DICE)}

DICE (https://dice-database.org/landing) was used to analyze the expression of $\mathrm{E} 2 \mathrm{~F} 1 / 2 / 4$ in various immune cells.

\section{TIMER and STRING database analysis}

TIMER (https://cistrome.shinyapps.io/timer/) was used to estimate immune infiltrates. In this study, E2FS expression have correlation with immune infiltrates, including B cells, $\mathrm{CD}^{+} \mathrm{T}$ cells, $\mathrm{CD} 8^{+} \mathrm{T}$ cells. The related marker genes on the $\mathrm{y}$ axis as gene symbols, the E2FS was used for the $\mathrm{x}$ axis with gene symbols. The expression level of gene was displayed with $\log 2$ RSEM. SCNAs in TIMER database are defined by GISTIC 2.0. Protein-protein interactions were predicted by STRING database (https://string-db.org/cgi/ about?footer_active_subpage=content). 


\section{The Cancer Genome Atlas (TCGA) data and cBioPortal}

TCGA including 30 different kinds of cancer types, and also had both sequencing and pathological data (22). cBioPortal (http://www.cbioportal.org/index.do?session $\mathrm{id}=5 \mathrm{a} 37 \mathrm{ba} 8 \mathrm{e} 498 \mathrm{eb} 8 \mathrm{~b} 3 \mathrm{~d} 56242 \mathrm{fb}$ ) was used to analyses of E2Fs in the stomach adenocarcinoma (TCGA, Provisional) dataset. cBioPortal's online instruction was used to calculate E2Fs network and co-expression.

\section{Tissue immunohistochemistry for E2F1 and E2F2 expression}

The study was conducted in accordance with the Declaration of Helsinki (as revised in 2013). Tumor tissues and corresponding non-tumor-adjacent tissues of GC patients were selected in Biobank of Zhejiang Cancer Hospital. The clinical features of the patient including age, gender, tumor stage, CEA and CA19-9 expression were derived from what was registered in our biobank. The Medical Ethics Committee, Zhejiang Medical College approved our study (No. IRB -2020-407). The immunohistochemical staining kit (PV9001, Beijing Zhongshan Golden Bridge Biotechnology Co. Ltd.) was used for this study. E2F1 (No. sc-56661, Santa Cruz) and E2F2 antibody (No. Sc-9967, Santa Cruz) (1:100) was added to each section. Considering the retrospective design of our study, the informed consent was waived.

\section{Quantitative real-time PCR}

Mini Kit (Qiagen) was used for total RNA extracted. The primers for E2F1/2 and U6 were synthesized by Sangon Biotech (Shanghai, China). The primers for U6 were: 5'-CTCGCTTCGGCAGCACATATACT-3' and 5'-ACGCTTCACGAATTTGCGTGTC-3'. The primers for E2F1 were: 5'-GCCACTGACTCTGCCACCATAG-3' and 5'-CTGCCCATCCGGGACAAC-3'. The primers for E2F2 were: 5'-CCTTGGAGGCTACTGACAGC-3' and 5'-CCACAGGTAGTCGTCCTGGT-3'. The primers for E2F4 were: 5'-GACCCCACAGGTGTTTTG-3' and 5'-CCAGGTTGTAGATGTAATCG-3'.

\section{Statistical analysis}

Graphpad Prism software (Version 7.0) was used for statistical analysis. Patients were divided into two groups according to E2F1/2/4 expression (high vs. low) in Kaplan-
Meier Plotter online database. Kaplan-Meier survival plots were used to compare OS between the two groups. Hazard ratio (HR) values with $95 \% \mathrm{CI}$ and log-rank $\mathrm{P}$ values were calculated. The correlation between E2F1/2/4 expression and clinical features was analyzed using the quartile method. The differences between groups were analyzed by the Students' $t$-test. $\mathrm{P}<0.05$ was considered statistically significant.

\section{Results}

\section{Relationship between GC and the expression of E2Fs}

The GEPIA dataset was used to analyze the differences in the levels of E2F1/2/3/4/5/6/7 expression between GC and normal stomach tissues (Figure 1A,B). According to the results, E2F1, E2F2, E2F4, E2F5, and E2F6 were highly expressed in stomach adenocarcinoma compared with normal stomach tissues.

\section{E2F1/2/4 were up-regulated in patients with $G C$}

To confirm the expression of E2F1/2/4, we analyzed serum expression levels of E2F1, E2F2, CEA, and CA19-9. As shown in Figure $2 A$ showed, E2F1/2/4 were highly expressed in the serum of GC patients, and had higher sensitivity and specificity than CEA and CA199. The details were descripted in Table 1. Furthermore, gastric tumor tissues and corresponding adjacent nontumor gastric tissues (10 pairs) were used to confirm E2F1 and E2F2 expression. IHC staining showed abundant and uniform expression of E2F1/2 proteins in tumor samples (Figure 2B). Additionally, the expression levels of E2F1, $\mathrm{E} 2 \mathrm{~F} 2$ and E2F4 were numerically higher in patients with advanced stages (stage III or IV) compared to those with stage I or II, with a statistically significant difference in E2F4 expression between the two groups $(\mathrm{P}<0.05$, Table 2$)$.

\section{Prediction of patbways and functions based on changes in E2F1/2/4}

The cBioPortal online tool was used to analyze the alterations, correlations, and networks associated with E2Fs. E2Fs were found to be altered in 328 samples out of 634 patients with GC (40\%). Additionally, out of 164 samples, in approximately half of the samples, 2 or more alterations were detected (Figure $3 A, B$ ). Furthermore, we explored E2F mRNA expression (RNA Seq V2 RSEM). The online 
A

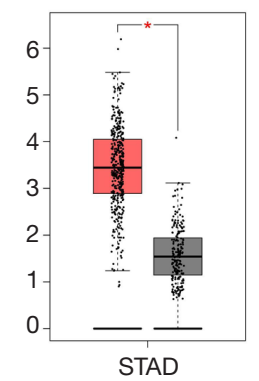

[num $(T)=408, \operatorname{num}(N)=211]$

E2F1

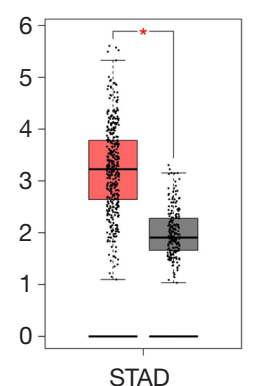

$[\operatorname{num}(\mathrm{T})=408, \operatorname{num}(\mathrm{N})=211]$

E2F5

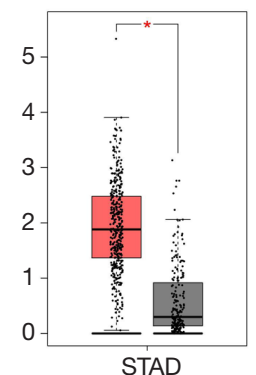

$[\operatorname{num}(\mathrm{T})=408, \operatorname{num}(\mathrm{N})=211]$

E2F2

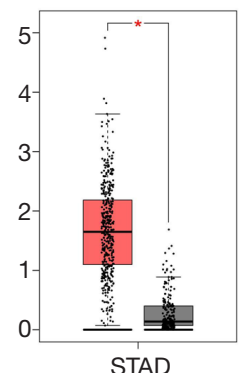

$[\operatorname{num}(\mathrm{T})=408, \operatorname{num}(\mathrm{N})=211]$

E2F6

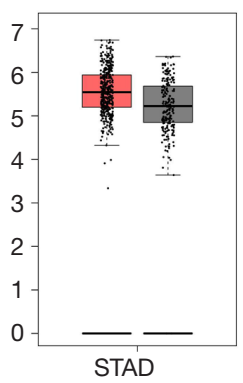

[num( $(T)=408, \operatorname{num}(N)=211]$

E2F3

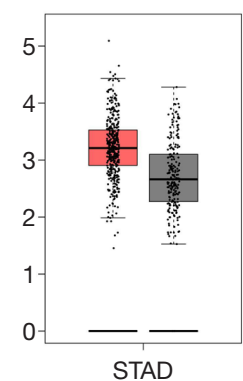

$[\operatorname{num}(\mathrm{T})=408, \operatorname{num}(\mathrm{N})=211]$

E2F7

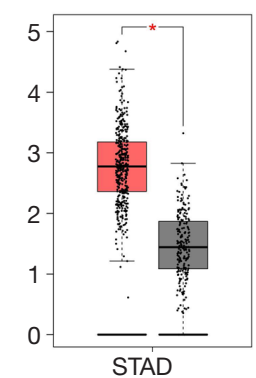

$[\operatorname{num}(\mathrm{T})=408, \operatorname{num}(\mathrm{N})=211]$

E2F4

B

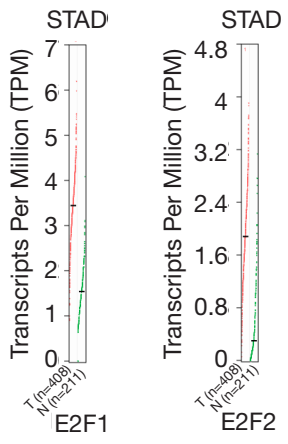

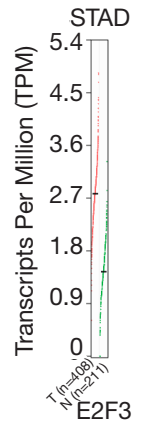
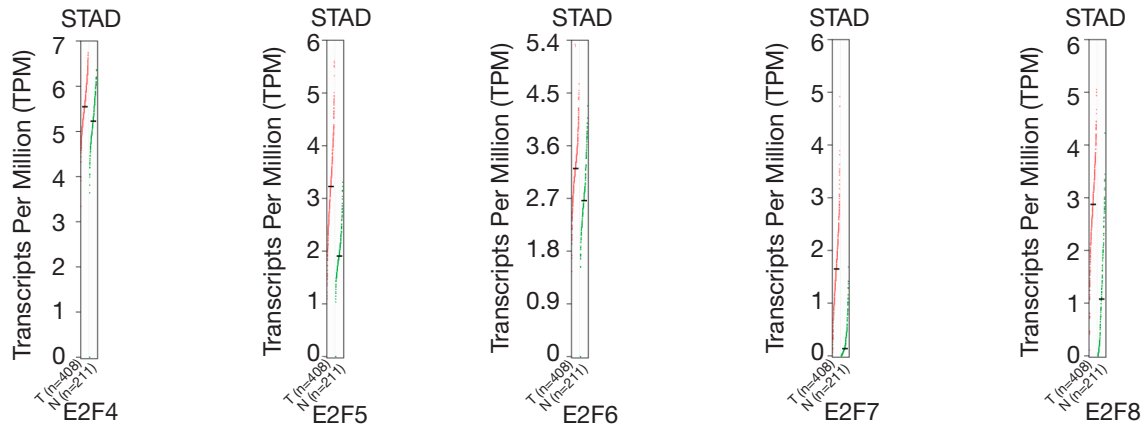

Figure 1 The expression of E2Fs in gastric cancer (GEPIA). (A,B) The higher expression levels of E2F1/2/4/5/6 in GC patients were represented as bar graphs and scatter plots, respectively. GC, gastric cancer. * $\mathrm{P}<0.05$.

cBioPortal tool was used to calculate the correlations among E2F1/2/4/5/7/8 in GC (TCGA, Provisional), including Pearson's correlation coefficient. This analysis revealed that E2F1 with E2F2, E2F2 with E2F1, and E2F7 and E2F8 showed significant positive correlations (Figure 3C). According to the Kyoto Encyclopedia of Genes and Genomes (KEGG) and Gene Ontology (GO) databases, the functions of E2Fs and their associated genes were concentrated in the cell cycle, the p53 signaling pathway, and cellular senescence regulation (Figure 3D,E, F, G). The E2Fs were correlated with wellestablished genes and pathways involved in various cell cycle processes.

\section{Expression of E2F1/2/4 in various types of immune cells}

We further constructed the frequently altered E2F1/2/4 neighboring gene regulatory network, which revealed that E2F1/2/4 was highly associated with cell cycle genes, such as CDK4 and CDK6 CCNE1, and CDKN2A (Figure $4 A$ ). A recent study indicated that $\mathrm{CDK} 4 / 6$ could control the production of neutrophil extracellular traps. Also, E2F1/2 could determine the threshold for antigen-induced $\mathrm{T}$ cell proliferation (12). Thus, we sought to explore the expression of E2F1, E2F2, and E2F4 in various immune cells. According to the immune cell database, E2F1/2 exhibited high expression in $\mathrm{CD}^{+} \mathrm{T}$ cells and macrophages 
A
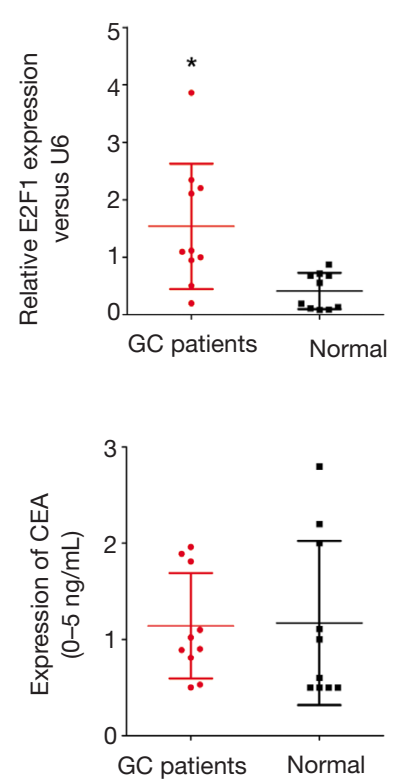

B

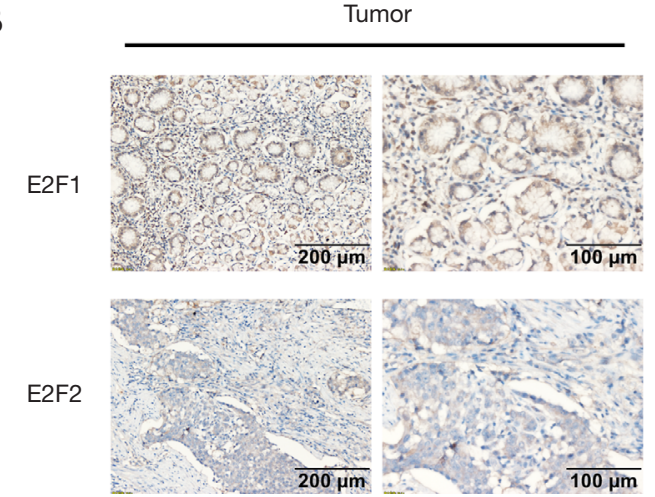

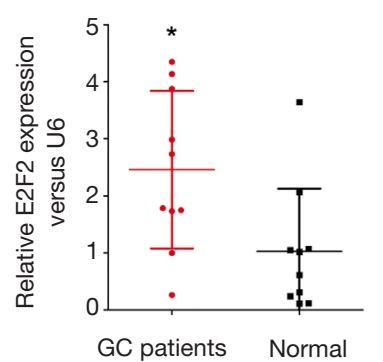

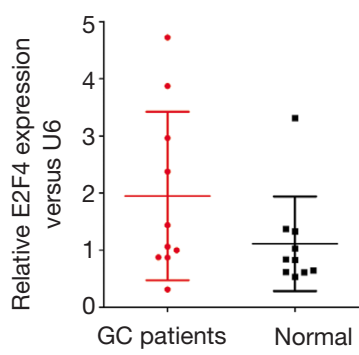

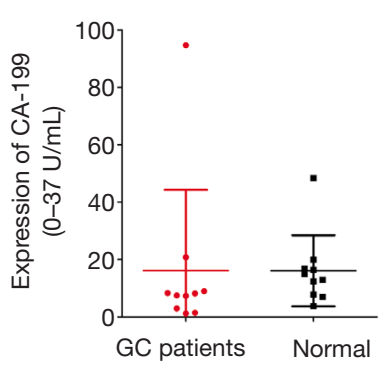
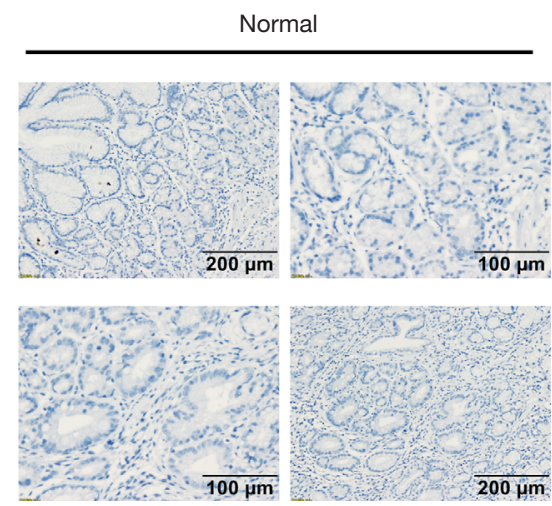

Figure 2 High expression levels of E2F1/2/4 in GC. (A) High expression levels of E2F1/2/4 in serum from patients with GC (n=10) compared to healthy individuals ( $\mathrm{n}=10)$. Expression levels were relative to control U6 expression. (B) E2F1/2 immunohistochemistry in gastric tumor and adjacent non-tumor gastric tissue. GC, gastric cancer. ${ }^{*}, \mathrm{P}<0.05$.

Table 1 Clinical features in gastric cancer patients (gastric) and healthy individuals (control)

\begin{tabular}{ccccccccc}
\hline Groups & Number & Age (years $)$ & Male & CEA $\left(P_{25}, P_{75}\right)$ & CA19-9 $\left(P_{25}, P_{75}\right)$ & E2F1 $\left(P_{25}, P_{75}\right)$ & E2F2 $\left(P_{25}, P_{75}\right)$ & E2F4 $\left(P_{25}, P_{75}\right)$ \\
\hline Gastric & 10 & $51.5(45,61.5)$ & $40 \%$ & $0.96(0.74,1.83)$ & $7.83(2.56,11.94)$ & $1.1(0.83,2.23)$ & $2.25(1.54,3.93)$ & $1.25(0.87,3.19)$ \\
Control & 10 & $46(31.7,53.5)$ & $40 \%$ & $0.8(0.5,2.0)$ & $13.98(7.61,17.59)$ & $0.373(0.10,0.68)$ & $0.81(0.21,1.31)$ & $0.83(0.61,1.33)$ \\
\hline
\end{tabular}

Table 2 Correlation between serum E2F1/2/4 expression and tumor stage in patients with gastric cancer

\begin{tabular}{lcccccc}
\hline & & E2F1 $\left(P_{25}, P_{75}\right)$ & E2F2 $\left(P_{25}, P_{75}\right)$ & E2F4 $\left(P_{25}, P_{75}\right)$ & CEA $\left(P_{25}, P_{75}\right)$ & CA19-9 $\left(P_{25}, P_{75}\right)$ \\
\hline UICC & I+II & $1.02(0.61,2.03)$ & $1.76(0.63,3.70)$ & $0.87^{\star}(0.45,1.01)$ & $0.67(0.50,1.67)$ & $7.41(2.73,8.01)$ \\
stage & III+IV & $1.61(0.79,2.61)$ & $2.85(1.54,3.93)$ & $2.67(1.32,4.08)$ & $1.06(0.89,1.83)$ & $8.63(2.56,39.27)$ \\
\hline
\end{tabular}

UICC, Union for International Cancer Control; *, $\mathrm{P}<0.05$. 


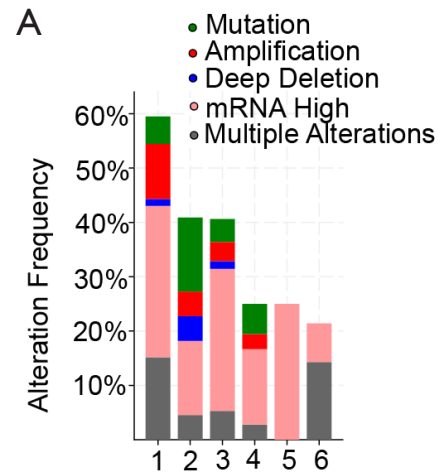

\section{B}

Genetic Alteration

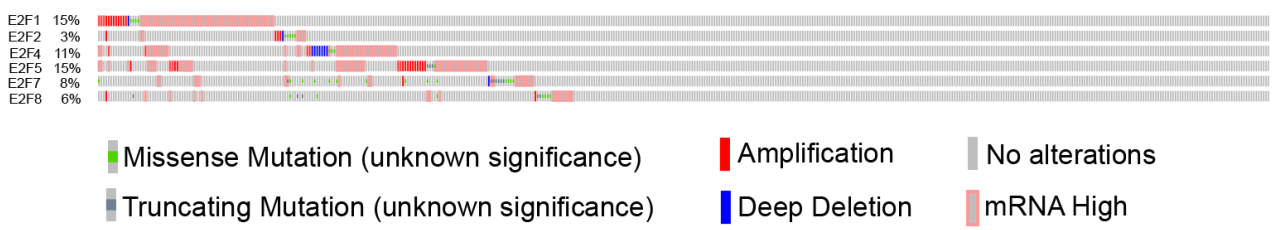

C

$\begin{array}{lcccccc} & E 2 F 1 & E 2 F 2 & E 2 F 4 & E 2 F 5 ~ & \text { E2F7 } & \text { E2F8 } \\ \text { E2F1 } & 1 & 0.549 & 0.378 & 0.224 & 0.466 & 0.499 \\ \text { E2F2 } & 0.549 & 1 & 0.229 & 0.184 & 0.533 & 0.584 \\ \text { E2F4 } & 0.378 & 0.229 & 1 & 0.426 & 0.405 & 0.321 \\ \text { E2F5 } & 0.224 & 0.184 & 0.426 & 1 & 0.305 & 0.242 \\ \text { E2F7 } & 0.466 & 0.533 & 0.405 & 0.305 & 1 & 0.58 \\ \text { E2F8 } & 0.499 & 0.584 & 0.321 & 0.242 & 0.58 & 1\end{array}$

1: Tubular Stomach Adenocarcinoma

2: Mucinous Stomach Adenocarcinoma

3: Stomach Adenocarcinoma

4: Diffuse Type Stomach Adenocarcinoma

5: Papillary Stomach Adenocarcinoma

6: Signet Ring Cell Carcinoma of the Stomach

D

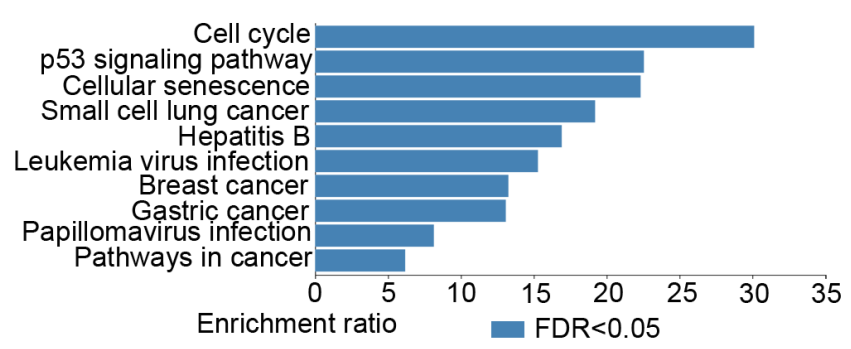

$E$

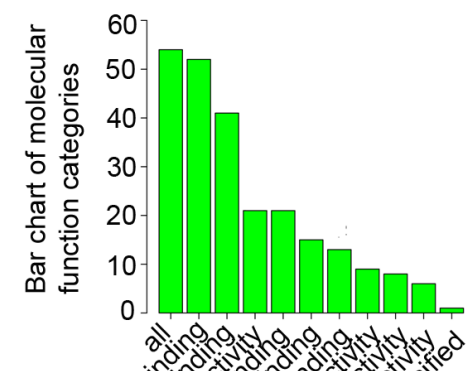

$\mathrm{F}$

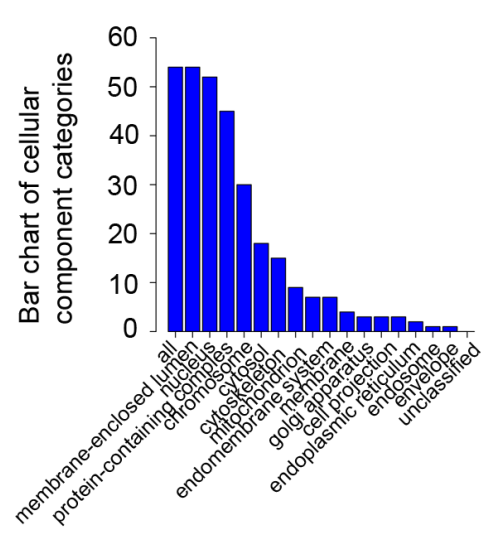

G
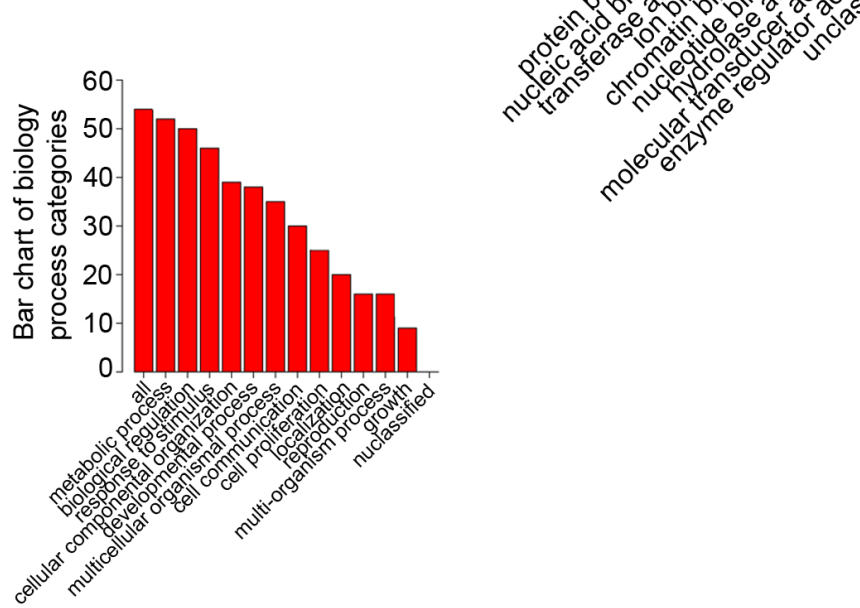

Figure 3 E2Fs mutation analysis and functions in GC. (A,B) Mutation analysis of E2Fs. (C) The interactions between E2F1/2/4/5/7/8. (D,E,F,G) GO analysis of the E2F-associated functions and pathways in GC. GC, gastric cancer; GO, Gene Ontology.

(Figure $4 B, C$ ), whereas E2F4 was highly expressed in $\mathrm{CD}^{+}{ }^{+} \mathrm{T}$ cells and $\mathrm{CD}^{+} \mathrm{T}$ cells (Figure $4 D$ ). These results suggested that the expression of E2F1/2/4 was closely correlated with $\mathrm{CD}^{+}{ }^{+} \mathrm{T}$ cells.

\section{E2F1/2/4 expression is correlated with the level of immune infiltration in $G C$}

Furthermore, we explored the association between E2F1/2/4 and the level of immune infiltration and patient prognosis 
A

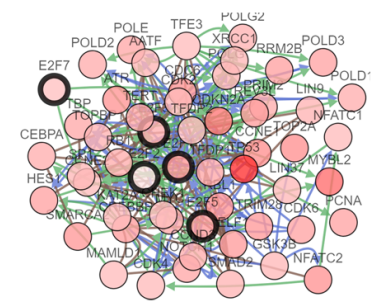

B

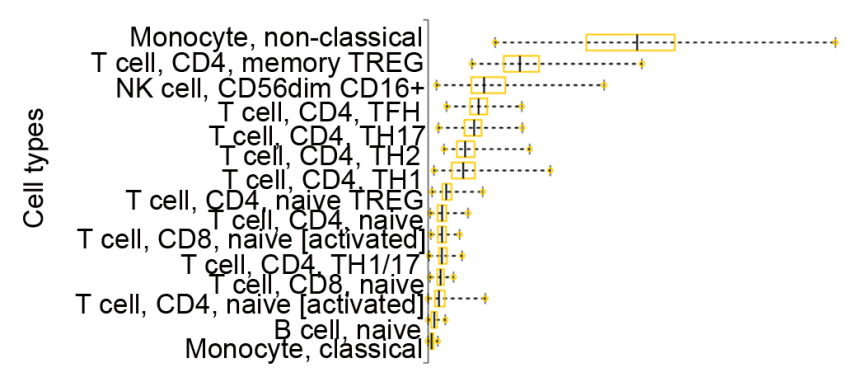

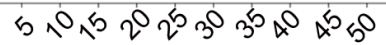

Transcripts per million of E2F1

D

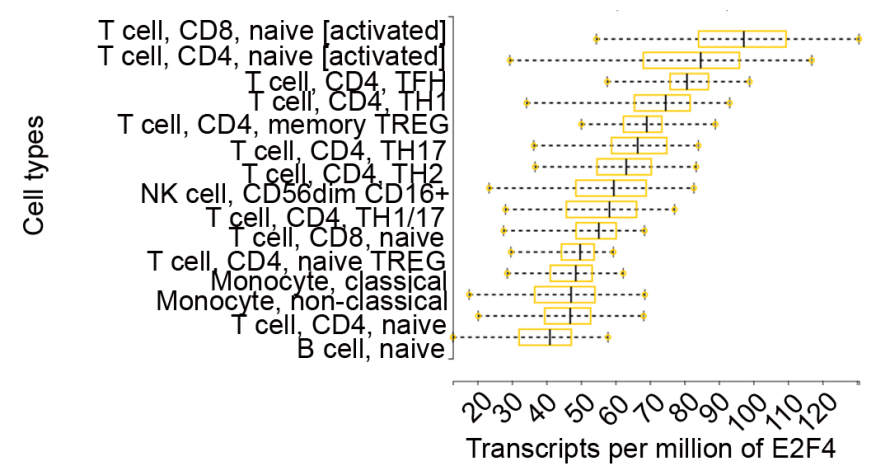

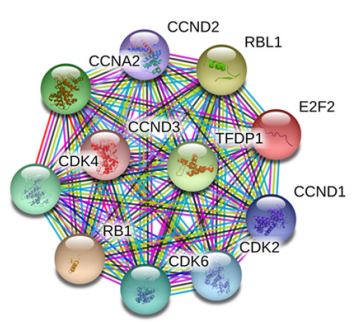

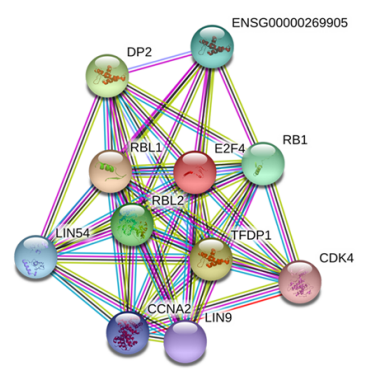

C

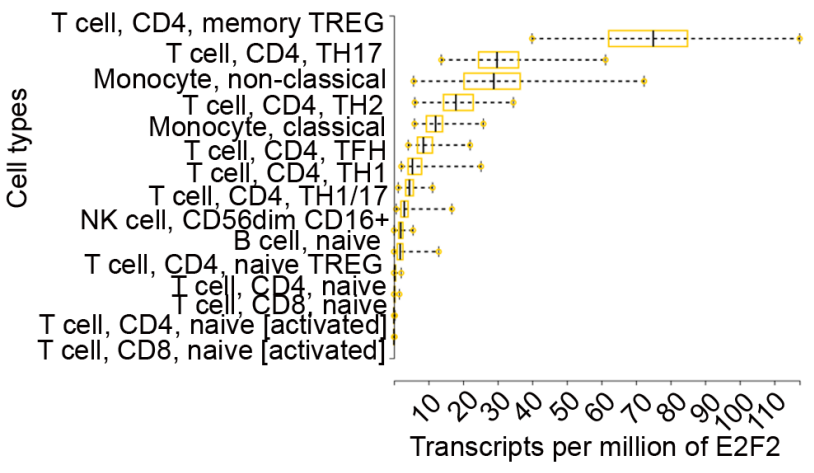

Figure 4 Bioinformatics analysis of the regulatory network and expression of E2F1/2/4 in immune cells. (A) E2F1/2/4 interaction with CDK2/4/6. (B) E2F1 is highly expressed in monocyte cells and T cell CD4 memory TREGs. (C) E2F2 is highly expressed in CD4 T memory TREGs and Th17 cells. (D) E2F4 is highly expressed in both CD4 and CD8 T cells.

in GC (23). Immune infiltration in clinical tumor samples using the genomic approach and the TIMER database was influenced by tumor purity (24-26). E2F1/2/4 was found to have a significant positive correlation with GC tumor purity (Figure 5A). Interestingly, the level of E2F1/2/4 expression was negatively correlated with infiltrating levels of $\mathrm{CD} 8^{+}$ $\mathrm{T}$ cells, $\mathrm{CD}^{+} \mathrm{T}$ cells, macrophages, B cells, neutrophils, and DCs in GC (Figure 5B). These results suggested that $\mathrm{E} 2 \mathrm{~F} 1 / 2 / 4$ played a specific role in immune infiltration in GC and suppressed tumorigenesis.

\section{E2F1/2/4 were significantly associated with the OS of patients with $G C$}

We further investigated the critical efficiency of E2Fs for the prognosis of GC patients. Kaplan-Meier Plotter tools (http://kmplot.com/) were used to analyze the correlation between the level of E2F1/2/4 mRNA and GC patient survival. Low E2F1/2/4 expression was highly correlated with a longer $\mathrm{OS}$ (all $\mathrm{P}<0.05$; Figure $6 A, B, C$ ). These findings suggested that $\mathrm{E} 2 \mathrm{~F} 1 / 2 / 4$ might have the potential to predict 

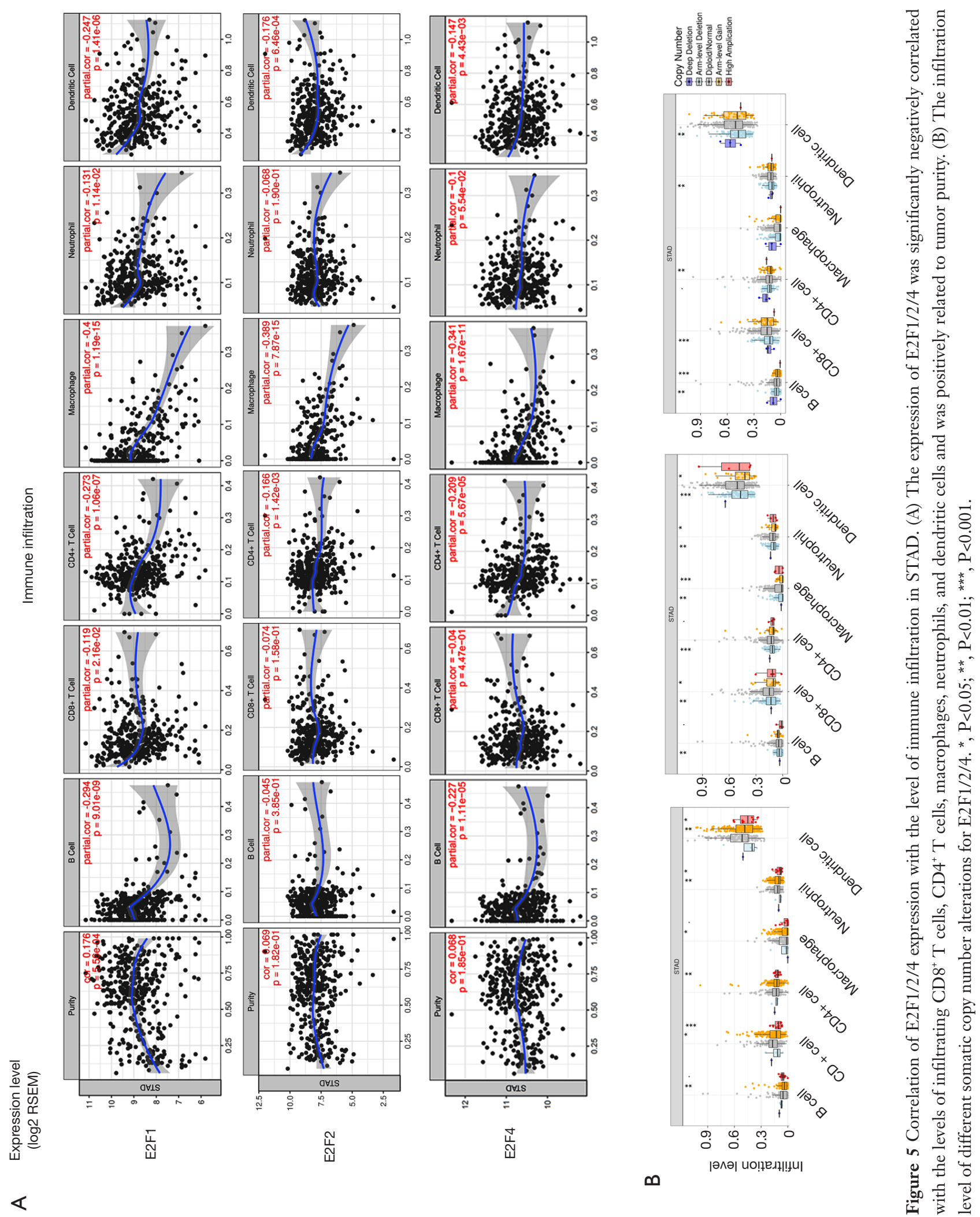
A

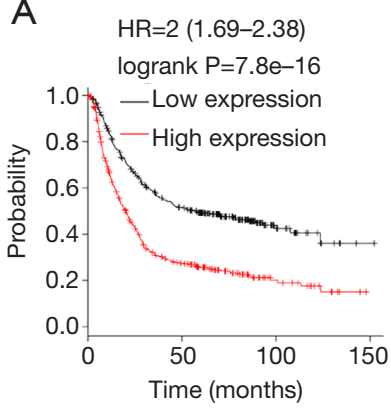

E2F1
B

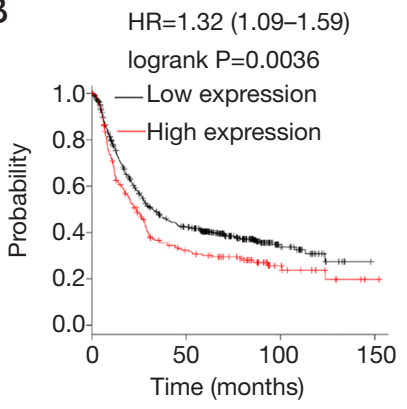

E2F2

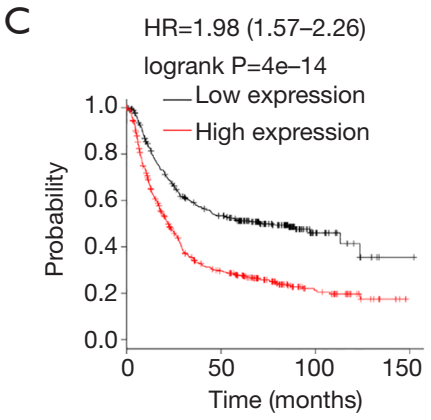

E2F4

Figure 6 High levels of E2F1/2/4 factor mRNA expression improved the survival probability of patients with GC. (A,B,C) The effect of high levels of E2F1/2/4 factor mRNA expression on the survival probability of gastric cancer patients using the Kaplan-Meier plotter. GC, gastric cancer.

the prognosis of patients with GC.

\section{Discussion}

It has been reported that E2Fs are dysregulated in various types of cancers (27-29). Recently, several reports have shown that E2Fs are involved in the tumorigenesis and prognosis of several cancers. However, few bioinformatics analyses of E2Fs have been performed. In this study, we showed the prognostic values of E2F1/2/4 in GC.

$\mathrm{E} 2 \mathrm{~F} 1$ is the most researched and investigated among all E2F members in the context of human cancers (30). Several studies indicate that E2F1 expression was significantly associated with a poor prognosis in several malignancies, including pancreatic, esophageal, and non-small cell lung cancer. Also, E2F1 has been reported to be a tumour suppressor in GC (31). However, in the present study, $\mathrm{E} 2 \mathrm{~F} 1$ was associated with the cell cycle and played a role in immune infiltration in GC.

E2F2 has been shown to play a critical role in several cellular processes, including differentiation, cell cycle, proliferation, and cancer development (32-34). As shown in a recent report, E2F2 was highly expressed in lung cancer tissues compared with normal tissues (35). Polymorphisms in the $\mathrm{E} 2 \mathrm{~F} 2$ promoter are associated with an increased risk of squamous cell carcinoma in the oropharynx, and various cancers were affected by E2F2 expression (36). In our study, low E2F1/24 expression was correlated with a longer OS in GC patients.

In patients with breast cancer, the E2F4 target genes exhibited high expression, which led to shorter survival and the development of more severe cancer (37). The methylation of E2F4 might also be of prognostic value in breast cancer through influencing its expression (38). Moreover, lung cancer patients with high expression of E2F4 showed a poor OS. In this study, high E2F4 expression was significantly correlated with immune infiltration, including macrophages, neutrophils, and DCs, which might have led to the poor OS of GC patients.

In this study, we analyzed and determined the expression and prognostic value of E2F1/2/4 in GC patients. We further investigated the complexity and heterogeneity of the molecular properties associated with GC. Additionally, increased E2F1/2/4 expression was found to play a special role in the cell cycle through interacting with CDK2/4/6. Our findings also suggested that the level of E2F1/2/4 expression was negatively correlated with infiltrating levels of $\mathrm{B}$ cells, $\mathrm{CD}^{+} \mathrm{T}$ cells, CD4 ${ }^{+} \mathrm{T}$ cells, macrophages, neutrophils, and DCs in GC. Thus, high E2F1/2/4 expression may also serve as a biomarker that can be used to identify high-risk subgroups of patients with GC.

\section{Conclusions}

We showed that E2F1/2 was highly expressed in the serum of GC patients. As predicted by bioinformatics, E2F1/2/4 was correlated with patient prognosis and immune cell infiltration and can be used as a prognostic biomarker and indicator of immune infiltration in GC.

\section{Acknowledgments}

Funding: This study was supported by the Zhejiang Province Public Welfare Technology Application Research 
Project (No. 2020KY058) and Zhejiang Province Public Welfare Technology Application Research Project (No. 2021KY082).

\section{Footnote}

Reporting Checklist: The authors have completed the MDAR reporting checklist. Available at https://dx.doi. org/10.21037/tcr-21-45

Data Sharing Statement: Available at https://dx.doi. org/10.21037/tcr-21-45

Conflicts of Interest: All authors have completed the ICMJE uniform disclosure form (available at https://dx.doi. org/10.21037/tcr-21-45). The authors have no conflicts of interest to declare.

Ethical Statement: The authors are accountable for all aspects of the work in ensuring that questions related to the accuracy or integrity of any part of the work are appropriately investigated and resolved. The study was conducted in accordance with the Declaration of Helsinki (as revised in 2013). The study was approved by the Ethics Committee of Zhejiang Cancer Hospital (No. IRB -2020407). Individual consent for this retrospective analysis was waived

Open Access Statement: This is an Open Access article distributed in accordance with the Creative Commons Attribution-NonCommercial-NoDerivs 4.0 International License (CC BY-NC-ND 4.0), which permits the noncommercial replication and distribution of the article with the strict proviso that no changes or edits are made and the original work is properly cited (including links to both the formal publication through the relevant DOI and the license). See: https://creativecommons.org/licenses/by-nc-nd/4.0/.

\section{References}

1. Torre LA, Bray F, Siegel RL, et al. Global cancer statistics, 2012. CA Cancer J Clin 2015;65:87-108.

2. You WC, Li JY, Blot WJ, et al. Evolution of precancerous lesions in a rural Chinese population at high risk of gastric cancer. Int J Cancer 1999;83:615-9.

3. Matsuoka T, Yashiro M. Biomarkers of gastric cancer: Current topics and future perspective. World J Gastroenterol 2018;24:2818-32.
4. Abbas M, Faggian A, Sintali DN, et al. Current and future biomarkers in gastric cancer. Biomed Pharmacother 2018;103:1688-700.

5. Ohtsu A, Ajani JA, Bai YX, et al. Everolimus for previously treated advanced gastric cancer: results of the randomized, double-blind, phase III GRANITE-1 study. J Clin Oncol 2013;31:3935-43.

6. Lordick F, Kang YK, Chung HC, et al. Capecitabine and cisplatin with or without cetuximab for patients with previously untreated advanced gastric cancer (EXPAND): a randomised, open-label phase 3 trial. Lancet Oncol 2013;14:490-9.

7. Ajani JA, D'Amico TA, Almhanna K, et al. Gastric Cancer, Version 3.2016, NCCN Clinical Practice Guidelines in Oncology. J Natl Compr Canc Netw 2016;14:1286-312.

8. Polager S, Kalma Y, Berkovich E, et al. E2Fs up-regulate expression of genes involved in DNA replication, DNA repair and mitosis. Oncogene 2002;21:437-46.

9. Lim CA, Yao F, Wong JJ, et al. Genome-wide mapping of RELA(p65) binding identifies E2F1 as a transcriptional activator recruited by NF-kappaB upon TLR4 activation. Mol Cell 2007;27:622-35.

10. Wu L, Timmers C, Maiti B, et al. The E2F1-3 transcription factors are essential for cellular proliferation. Nature 2001;414:457-62.

11. Sun CC, Li SJ, Hu W, et al. Comprehensive Analysis of the Expression and Prognosis for E2Fs in Human Breast Cancer. Mol Ther 2019;27:1153-65.

12. Azkargorta M, Fullaondo A, Laresgoiti U, et al. Differential proteomics analysis reveals a role for $\mathrm{E} 2 \mathrm{~F} 2$ in the regulation of the Ahr pathway in T lymphocytes. Mol Cell Proteomics 2010;9:2184-94.

13. Yamauchi S, Kawamura K, Okamoto S, et al. Replicationcompetent adenoviruses with the type 35-derived fiberknob region achieve reactive oxygen species-dependent cytotoxicity and produce greater toxicity than those with the type 5-derived region in pancreatic carcinoma. Apoptosis 2015;20:1587-98.

14. Li Y, Huang J, Yang D, et al. Expression patterns of E2F transcription factors and their potential prognostic roles in breast cancer. Oncol Lett 2018;15:9216-30.

15. Kunigal S, Ponnusamy MP, Momi N, et al. Nicotine, IFNgamma and retinoic acid mediated induction of MUC4 in pancreatic cancer requires E2F1 and STAT-1 transcription factors and utilize different signaling cascades. Mol Cancer 2012;11:24.

16. Deshpande AM, Akunowicz JD, Reveles XT, et al. PHC3, a component of the hPRC-H complex, associates with 
E2F6 during G0 and is lost in osteosarcoma tumors. Oncogene 2007;26:1714-22.

17. Yang H, Wang L, Tang X, et al. miR-203a suppresses cell proliferation by targeting E2F transcription factor 3 in human gastric cancer. Oncol Lett 2017;14:7687-90.

18. Liang B, Zhao J, Wang X. Clinical performance of E2Fs 1-3 in kidney clear cell renal cancer, evidence from bioinformatics analysis. Genes Cancer 2017;8:600-7.

19. Bollig-Fischer A, Marchetti L, Mitrea C, et al. Modeling time-dependent transcription effects of HER2 oncogene and discovery of a role for E2F2 in breast cancer cellmatrix adhesion. Bioinformatics 2014;30:3036-43.

20. Kang J, Lee HJ, Jun SY, et al. Cancer-Testis Antigen Expression in Serous Endometrial Cancer with Loss of $\mathrm{X}$ Chromosome Inactivation. PLoS One 2015;10:e0137476.

21. Gyorffy B, Lanczky A, Eklund AC, et al. An online survival analysis tool to rapidly assess the effect of 22,277 genes on breast cancer prognosis using microarray data of 1,809 patients. Breast Cancer Res Treat 2010;123:725-31.

22. Chen HZ, Tsai SY, Leone G. Emerging roles of E2Fs in cancer: an exit from cell cycle control. Nat Rev Cancer 2009;9:785-97.

23. Amulic B, Knackstedt SL, Abu Abed U, et al. Cell-Cycle Proteins Control Production of Neutrophil Extracellular Traps. Dev Cell 2017;43:449-62.e5.

24. Li T, Fu J, Zeng Z, et al. TIMER2.0 for analysis of tumor-infiltrating immune cells. Nucleic Acids Res 2020;48:W509-14.

25. Tang Z, Li C, Kang B, et al. GEPIA: a web server for cancer and normal gene expression profiling and interactive analyses. Nucleic Acids Res 2017;45:W98-W102.

26. Yoshihara K, Shahmoradgoli M, Martinez E, et al. Inferring tumour purity and stromal and immune cell admixture from expression data. Nat Commun 2013;4:2612.

27. Xanthoulis A, Tiniakos DG. E2F transcription factors and digestive system malignancies: how much do we know? World J Gastroenterol 2013;19:3189-98.

28. Huang CL, Liu D, Nakano J, et al. E2F1 overexpression correlates with thymidylate synthase and survivin gene

Cite this article as: Chen $\mathrm{Y}$, Gong W, Dai W, Jiang $\mathrm{H}, \mathrm{Xu} \mathrm{X}$. E2F1/2/4 mRNA is associated with immune infiltration and are potential biomarkers for the prognosis of human gastric carcinoma. Transl Cancer Res 2021;10(6):2801-2811. doi: $10.21037 /$ tcr-21-45 expressions and tumor proliferation in non small-cell lung cancer. Clin Cancer Res 2007;13:6938-46.

29. Yamazaki K, Yajima T, Nagao T, et al. Expression of transcription factor E2F-1 in pancreatic ductal carcinoma: an immunohistochemical study. Pathol Res Pract 2003;199:23-8.

30. Ebihara Y, Miyamoto M, Shichinohe T, et al. Overexpression of E2F-1 in esophageal squamous cell carcinoma correlates with tumor progression. Dis Esophagus 2004;17:150-4.

31. Manicum T, Ni F, Ye Y, et al. Prognostic values of E2F mRNA expression in human gastric cancer. Biosci Rep 2018;38:BSR20181264.

32. Suzuki DE, Nakahata AM, Okamoto OK. Knockdown of E2F2 inhibits tumorigenicity, but preserves stemness of human embryonic stem cells. Stem Cells Dev 2014;23:1266-74.

33. Reimer D, Sadr S, Wiedemair A, et al. Expression of the E2F family of transcription factors and its clinical relevance in ovarian cancer. Ann N Y Acad Sci 2006;1091:270-81.

34. Reimer D, Sadr S, Wiedemair A, et al. Clinical relevance of E2F family members in ovarian cancer--an evaluation in a training set of 77 patients. Clin Cancer Res 2007;13:144-51.

35. Sun CC, Zhou Q, Hu W, et al. Transcriptional E2F1/2/5/8 as potential targets and transcriptional $\mathrm{E} 2 \mathrm{~F} 3 / 6 / 7$ as new biomarkers for the prognosis of human lung carcinoma. Aging (Albany NY) 2018;10:973-87.

36. Li Y, Sturgis EM, Zhu L, et al. E2F transcription factor 2 variants as predictive biomarkers for recurrence risk in patients with squamous cell carcinoma of the oropharynx. Mol Carcinog 2017;56:1335-43.

37. Qiu M, Liang Z, Chen L, et al. MicroRNA-429 suppresses cell proliferation, epithelial-mesenchymal transition, and metastasis by direct targeting of BMI1 and E2F3 in renal cell carcinoma. Urol Oncol 2015;33:332.e9-18.

38. Schwemmle S, Pfeifer GP. Genomic structure and mutation screening of the $\mathrm{E} 2 \mathrm{~F} 4$ gene in human tumors. Int J Cancer 2000;86:672-7. 